\title{
QUALIDADE DA VINCULAÇÃO E DOS RELACIONAMENTOS SIGNIFICATIVOS NA GRAVIDEZ*
}

\author{
Bárbara Figueiredo ${ }^{1}$ \\ Alexandra Pacheco ${ }^{2}$ \\ Raquel Costa ${ }^{3}$ \\ Rute Magarinho ${ }^{4}$
}

Resumo: O estudo apresentado neste artigo destinou-se a investigar a qualidade da vinculação e das relações significativas na gravidez. Mais precisamente, teve por objectivos (1) determinar as características sociais e demográficas e as condições anteriores de existência que se associam e permitem prever um estilo de vinculação (in)seguro e (2) estimar o impacto do estilo de vinculação na qualidade do relacionamento e do apoio por parte do companheiro e de uma outra pessoa significativa, na gravidez.

Uma amostra de 130 grávidas (66 adolescentes e 64 adultas) foi avaliada no último trimestre de gestação quanto ao estilo de vinculação e à qualidade do relacionamento e do apoio por parte do companheiro e de uma outra pessoa significativa (com base na Attachment Style Interview, ASI; Bifulco, Figueiredo, Guedeney, Gorman, Hays et al., 2004; Bifulco, Moran, Ball \& Bernazzani, 2002a; Bifulco, Moran, Ball \& Lillie, 2002b). A amostra foi recolhida na Maternidade de Júlio Dinis (Porto) e é bastante heterogénea do ponto de vista social e demográfico, em características como: a idade, o nível educacional, o estado civil, o estatuto ocupacional e o tipo de agregado familiar, embora fundamentalmente constituída por grávidas primíparas.

Os resultados mostram que um estilo inseguro de vinculação pode ser previsto na sequência de separação ou divórcio parental durante a infância ou adolescência e

\footnotetext{
* Agradecimentos: Queremos agradecer a todas as mães que voluntariamente participaram neste estudo. Queremos também agradecer às Dr. ${ }^{\text {as }}$ Ana Marques, Ana Rodrigues e Cristina Cabeleira, que colaboraram na recolha dos dados a seguir apresentados. Apoios: Serviço de Saúde e Desenvolvimento Humano da Fundação Calouste Gulbenkian (Proc. 48914/02-04) e Fundação para a Ciência e Tecnologia (POCTI/SAU/14109/1998). A correspondência deve ser enviada para: Bárbara Figueiredo, Departamento de Psicologia, Universidade do Minho, Campus de Gualtar, 4710-057 Braga. bbfi@iep.uminho.pt.

${ }^{1}$ Professora Associada no Departamento de Psicologia da Universidade do Minho.

2 Mestre em Psicologia Clínica. Investigadora no Departamento de Psicologia da Universidade do Minho e na Maternidade de Júlio Dinis.

${ }^{3}$ Mestre em Psicologia Clínica. Investigadora no Departamento de Psicologia da Universidade do Minho e na Maternidade de Júlio Dinis.

${ }^{4}$ Médica Obstetra. Directora do Serviço de Obstetrícia da Maternidade de Júlio Dinis.
}

PSICOLOGIA, Vol. XX (1), 2006, Edições Colibri, Lisboa, pp. 65-96 
quando a grávida está desempregada, e que a gravidez na adolescência se associa ao estilo de vinculação desligado. Mostram ainda que um estilo inseguro de vinculação permite prever um pior relacionamento na gravidez, quer com o companheiro, quer com a outra pessoa significativa, principalmente a presença de relações discordantes com o companheiro e de relações apáticas com a outra pessoa significativa. As estratégias emaranhadas afectam a relação com o companheiro (em aspectos como menos confiança, menos suporte emocional e mais interacção negativa), mas não a relação com a outra pessoa significativa; enquanto as estratégias desligadas afectam a relação com a outra pessoa significativa (em aspectos como menos actividades partilhadas e menos interacção positiva), mas não a relação com o companheiro, e as estratégias amedrontadas afectam o relacionamento, tanto com o companheiro (em aspectos como menor sentimento de ligação) quanto com a outra pessoa significativa (em aspectos como menos confiança).

De acordo com a Teoria da Vinculação, conclui-se que condições adversas de existência (anteriores e actuais) propiciam vinculação insegura e que o estilo de vinculação interfere na qualidade do relacionamento com o companheiro e com outras pessoas significativas, nomeadamente na capacidade da grávida recorrer a apoio.

Palavras-chave: gravidez; vinculação; relacionamento com o companheiro; relacionamento com outros significativos

\begin{abstract}
Attachment and significant relationship's quality during pregnancy (Abstract): This study is aimed to investigate the quality of the pregnant woman's attachment and significant relationships during pregnancy. More precisely it intends (1) to determine social and demographic characteristics as well as previous conditions of existence that may predict an (in)secure attachment style (2) to estimate the attachment style's impact on the quality of the relationship and support by the partner and another significant person, during pregnancy. A sample of 130 pregnant women (66 adolescents and 64 adults) was evaluated in the last trimester of gestation on the attachment style and on the quality of the relationship and support from the partner and another significant person (on the basis of the Attachment Style Interview, ASI, Bifulco, Figueiredo, Guedeney, Gorman, Hays, et al., 2004; Bifulco, Moran, Ball \& Bernazzani, 2002a; Bifulco, Moran, Ball \& Lillie, 2002b). The sample was collected at the Júlio Dinis Maternity Hospital (Porto, Portugal) and is very heterogeneous regarding social and demographic characteristics, such as: age, educational level, marital status, occupational status and family unit, though it is mainly composed of primiparous pregnant.

The results showed that the pregnant childhood parental divorce/separation and present unemployment predict an insecure attachment style, and an association between teen pregnancy and an dismissing attachment style. The results also showed that an insecure attachment style predicts a worse relationship with the partner, as well as a worse relationship with the significant other, principally the presence of discordant relationships with the partner and of apathetic relationships
\end{abstract}


with the significant other. Enmeshed strategies affects the relationship with the partner (in aspects as less trust, poor emotional support and more negative interaction), but not with the significant other, while dismissive strategies affect the relationship with the significant other (in aspects as less shared activities and poor positive interaction), but not with the partner, and fearful strategies affect both the relationship with the partner (in aspects as poor attachment) and the relationship with the significant other (in aspects as less trust).

One concludes according to attachment theory that previous and present adverse conditions of existence increase attachment insecurity and that attachment style interferes in the quality of the relationship with the partner and with significant others, namely in the pregnant ability to seek support.

Key-words: attachment; pregnancy; relationship with partner; relationships with significant others

\section{Introdução}

Segundo a Teoria da Vinculação, o indivíduo interpreta os acontecimentos da sua existência e estabelece formas de agir no mundo, nomeadamente na relação com os outros significativos, com base nas expectativas a respeito do próprio, do outro e da relação com o outro, geradas na interacção com os pais durante a infância (Bowlby, 1988). Tais representações mentais, conscientes e inconscientes, do próprio, do outro e da relação com o outro (working models), ajudam o indivíduo a compreender os acontecimentos e a antever e arquitectar planos de acção (Bowlby, 1973). Determinam, por conseguinte, a forma como se relaciona com os outros, principalmente em momentos de maior stress ou dificuldade, quando o sistema de vinculação é activado (Sroufe \& Waters, 1977).

Basicamente, foram descritos modelos seguros, quando o indivíduo acredita na acção do próprio e tem expectativas positivas a respeito do/da relação com o outro, na satisfação das suas necessidades, e modelos inseguros, quando tal não acontece. Neste último caso, os modelos podem ser evitantes/desligados, quando o sujeito valoriza excessivamente o próprio, minimizando a necessidade do/da relação com o outro, ou preocupados/emaranhados/ambivalentes, quando tem expectativas negativas a respeito do próprio e irrealistas a respeito do/da relação com o outro, maximizando a sua necessidade. Bartholomew e Horowitz (1991) consideram ainda a presença de um estilo amedrontado, quando os modelos do próprio e do outro são ambos negativos.

Alguns autores têm procurado testar o contributo das variáveis socio-demográficas e das experiências negativas de existência, passadas 
(principalmente o abuso e a negligência) e presentes, para o estilo de vinculação do indivíduo (e.g., Alexander, 1992; Beckwith, Cohen \& Hamilton, 1999; Cozzarelli, Karafa, Collins \& Tagler, 2003; Michelson, Kessler \& Shaver, 1997). Um outro importante corpo de estudos empíricos tem mostrado que o estilo de vinculação do indivíduo interfere na vivência e determina a qualidade do relacionamento com pessoas significativas (Feeney, 1999, para uma revisão). Os indivíduos seguros, sendo mais capazes de manter relacionamentos significativos, têm geralmente relações mais ajustadas, com níveis mais elevados de confiança, satisfação e intimidade; enquanto que os sujeitos inseguros, quando evitantes, têm mais rupturas, menos satisfação e menor intimidade e, quando preocupados, tendem a reportar mais dificuldades ou conflitos, nomeadamente na relação com o companheiro (e.g., Bifulco, Moran, Ball \& Bernazzani, 2002a; Bifulco, Moran, Ball \& Lillie, 2002b; Bifulco, Figueiredo, Guedeney, Gorman, Hays et al., 2004; Brennan \& Shaver, 1995; Feeney \& Noller, 1990; Feeney, Noller \& Callan, 1994; Hazan \& Shaver, 1987; Kickpatrick \& Hazan, 1994; Koback \& Hazan, 1991; Levy \& Davis, 1988; Eiden, Teti \& Corns, 1995; McCarthy \& Taylor, 1999; Pacheco, Costa \& Figueiredo, 2003; Rholes, Simpson, Campbell \& Grich, 2001; Simpson, 1990).

A gravidez é um importante momento de transição na vida da mulher e proporciona uma oportunidade única de mudança e desenvolvimento. Promove um conjunto significativo de aquisições desenvolvimentais, nomeadamente porque motiva um movimento de reaproximação com a família de origem, o que facilita a revisão da relação com os pais, no passado e no presente (Figueiredo, 2005). Na medida em que estimula a revisão da relação com os pais (Ammaniti, Baumgartner, Canderoli, Peruchini, Pola et al., 1992; Vizziello, Antonioli, Cocci \& Invernizzi, 1993), possibilita que a mesma seja representada de uma forma mais coerente e organizada, beneficiando, portanto, a aquisição de segurança ao nível da vinculação (Pacheco et al., 2003).

Mas, enquanto período de transição, a gravidez implica não só um elevado número de mudanças, como determina também um nível acrescido de stress e mal-estar (Geller, 2004). A mulher tende, por isso, a necessitar mais do apoio e da proximidade dos outros. $\mathrm{O}$ estilo de vinculação é, por consequência, um aspecto que pode interferir na adaptação da mulher nesta nova fase da sua vida. Dado que influencia a qualidade das relações significativas, o modo como a grávida se coloca perante o apoio e o suporte dos envolventes vai determinar, em muito, a forma como se adapta e as dificuldades que pode sentir (Feeney, Alexander, Noller \& Hohaus, 2003). Com efeito, evidências empíricas recentes mostram que o estilo de vinculação (Besser, Priel \& Wiznitzer, 2002; Bifulco et al., 2004; Feeney et al., 2003) e a qualidade das relações significativas, particularmente com o compa- 
nheiro (e.g., Ritter, Hobfoll, Lavin, Cameron \& Hulsizer, 2000; Rubertsson, Waldenstroem \& Wickberg, 2003), são dimensões que importam para o bem-estar da mulher na gravidez e pós-parto. Sobretudo quando se tem verificado que a transição para a parentalidade pode interferir negativamente na relação conjugal, pois, muitas vezes, faz-se acompanhar de uma diminuição da proximidade e dos sentimentos amorosos e de um aumento dos conflitos e da ambivalência entre os elementos do casal (e.g., Belsky, Rovine \& Fish, 1989; Fleming, Ruble, Flett \& van Wagner, 1990). Outros estudos mostram ainda que é particularmente determinante para a saúde mental da grávida/puérpera a qualidade da sua relação com os elementos femininos do seu ambiente, designadamente com a própria mãe (Matthey, Barnett, Ungerer, Waters, 2000; Pajulo, Savonlahti, Sourander, Helenius \& Piha, 2001; Pajulo, Savonlahti, Sourander, Piha \& Helenius, 2001).

Tal como prevê a Teoria da Vinculação, o estilo de vinculação é um elemento relevante na adaptação do indivíduo à realidade, em particular quando são maiores as exigências desenvolvimentais e/ou o sistema de vinculação é activado, por isso, presumivelmente mais determinante na transição para a parentalidade. Uma das vias pela qual esta relação pode funcionar reside no facto de, sobretudo em momentos de maior stress ou vulnerabilidade, quando a adaptação do indivíduo mais depende da mobilização do suporte, as estratégias de vinculação influenciarem o modo como se relaciona e recorre aos outros para apoio.

Justifica-se, assim, o objectivo deste estudo investigar a qualidade da vinculação e das relações significativas na gravidez, no que concerne: 1) às características sociais e demográficas e às condições anteriores de existência que se associam e permitem predizer o estilo (in)seguro de vinculação; 2) ao impacto do estilo de vinculação na qualidade do relacionamento e do apoio por parte do companheiro e de uma outra figura significativa, nomeadamente as diferenças na qualidade das relações significativas em grávidas com diferentes estilos de vinculação.

\section{Método}

\section{Participantes}

A selecção das participantes decorreu na Consulta Externa do Serviço de Obstetrícia da Maternidade de Júlio Dinis (MJD, Porto), tendo em conta o tempo de gestação: entre a $24 .^{\mathrm{a}}$ e a $36 .^{\mathrm{a}}$ semanas.

A amostra é constituída por um total de 130 grávidas, adolescentes $(\mathrm{N}=66)$ e adultas $(\mathrm{N}=64)$, entre os 14 e os 40 anos de idade $(\mathrm{M}=22,6$, $\mathrm{DP}=7,33)$, quase todas de nacionalidade portuguesa $(94,6 \%)$ e de etnia caucasiana (98,5\%) (cf. Quadro 1). A maioria não tem a escolaridade obri- 
gatória, no entanto, algumas frequentaram/terminaram o ensino secundário ou superior. Embora uma parte considerável da amostra esteja desempregada, mais de metade está empregada ou a estudar. As profissões são diversificadas, mas, em quase metade dos casos, do tipo manual não especializado. Muitas grávidas são casadas ou vivem em regime de coabitação; $27,7 \%$ são contudo solteiras. Somente $1 / 4$ das mães vive sozinha com o companheiro $(26,9 \%)$, pelo que grande parte coabita com mais elementos da família $(73,1 \%)$. O pai do bebé geralmente integra o agregado familiar. A maioria dos companheiros trabalha $(85,6 \%)$; as profissões são correntemente do tipo manual, especializado $(30,8 \%)$ ou não especializado $(31,6 \%)$. Em termos dos antecedentes pessoais, é de referir que algumas mães já tiveram um filho, assim como a presença de condições de existência adversas antes dos 18 anos de idade: divórcio ou separação dos pais, separação sem contacto com pelo menos um dos pais durante mais de um ano e morte de um ou de ambos os pais.

\section{Instrumentos}

Foi utilizado uma entrevista social e demográfica, com o objectivo de recolher dados relativos à grávida e ao companheiro, que engloba os seguintes aspectos: idade, naturalidade, escolaridade, profissão, estado civil, agregado familiar e antecedentes pessoais (Figueiredo, Pacheco \& Magarinho, 2005).

A qualidade do estilo de vinculação e do suporte social e das relações interpessoais significativas foi estudada através da Attachment Style Interview (ASI, Bifulco et al., 2004; Bifulco et al., 2002a,b). A ASI consiste numa entrevista semi-estruturada composta por duas partes: uma que se destina à classificação do estilo de vinculação e outra que permite a avaliação da qualidade do relacionamento com figuras de suporte significativas.

$\mathrm{O}$ investigador aprecia as referidas dimensões, recorrendo à gravação áudio da entrevista e utiliza uma escala de tipo Likert para a cotação de cada subescala (que, na maior parte dos casos, varia entre: 'acentuada', 'moderada', 'alguma' e 'pouca/nenhuma') e da escala global. Na avaliação do estilo de vinculação, a $A S I$ considera 8 dimensões específicas (subescalas): 'desconfiança', 'constrangimentos atitudinais à proximidade', 'medo da intimidade', 'individualismo', 'desejo de envolvimento/emaranhamento', 'falta de tolerância à separação' e 'capacidade do sujeito para iniciar e manter relações interpessoais'. O estilo de vinculação pode ser classificado 
atendendo à categorização em: 1) seguro versus inseguro; 2) emaranhado, desligado, amedrontado ou retraído 5 .

Quadro 1: Caracterização da amostra

\begin{tabular}{|c|c|c|}
\hline & & $\begin{array}{c}N=130 \\
\%\end{array}$ \\
\hline \multirow{20}{*}{ 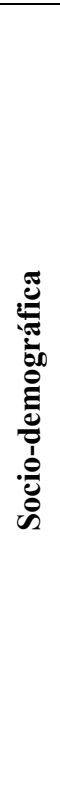 } & Idade & \\
\hline & $\leq 18$ anos & 50,8 \\
\hline & $>18$ anos & 49,2 \\
\hline & Anos de Estudo & \\
\hline & $<9^{\circ}$ ano & 73,8 \\
\hline & $9-12 .^{\circ}$ ano & 15,4 \\
\hline & $>12 .^{\circ}$ ano & 10,8 \\
\hline & Estado Civil & \\
\hline & Casada & 50,8 \\
\hline & Em regime de Coabitação & 21,5 \\
\hline & Solteira & 27,7 \\
\hline & Situação Profissional & \\
\hline & Empregada & 52,4 \\
\hline & Estudante & 11,3 \\
\hline & Desempregada & 36,3 \\
\hline & Profissão & \\
\hline & Manual não especializada & 48,9 \\
\hline & Manual especializada & 7,6 \\
\hline & Não manual não especializada & 27,2 \\
\hline & Não manual especializada & 16,3 \\
\hline \multirow{4}{*}{ 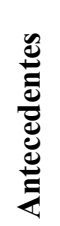 } & Multiparidade & 29,2 \\
\hline & Morte de um ou de ambos os pais & 10,0 \\
\hline & Separação ou divórcio parental & 23,1 \\
\hline & Separação dos pais por mais de 1 ano & 20,8 \\
\hline
\end{tabular}

Bifulco, Lillie, Ball \& Moran (1988) definiram cinco estilos de vinculação, aquando da construção da $A S I$, do modo que descrevemos a seguir.

\footnotetext{
${ }^{5}$ A ASI permite ainda avaliar o grau de disfuncionalidade da vinculação (marcadamente, moderadamente ou ligeiramente inseguro ou claramente seguro); ou seja, o grau em que o estilo de vinculação reflecte as dificuldades no relacionamento interpessoal do indivíduo. Um sujeito com estilo inseguro de vinculação pode ter dois níveis de disfuncionalidade: marcadamente ou moderadamente inseguro; por sua vez, os sujeitos seguros podem ser claramente ou ligeiramente inseguros.
} 
Emaranhado: é um estilo de vinculação dependente, frequentemente acompanhado por hostilidade e raiva, bem como por ambivalência ou manipulação na relação com os outros. Os sujeitos classificados com um estilo de vinculação emaranhado têm elevada necessidade de dependência e requerem muita atenção dos outros, podem, contudo, ter muito poucos relacionamentos verdadeiramente próximos. Frequentemente, parecem contradizer-se no relato e o estilo de narração tem tendência a ser cheio, emocional e propenso ao exagero.

Desligado: é um estilo de vinculação caracterizado pelo evitamento, elevado individualismo e raiva ou intolerância para com os outros. Os sujeitos classificados com um estilo de vinculação desligado podem escolher contar apenas consigo e são frequentemente contenciosos com os outros ou clamam que não se pode confiar em ninguém. Geralmente, isolam-se, sendo mais difíceis no relacionamento que o tipo amedrontado. $\mathrm{O}$ estilo narrativo tende a ser breve e lacónico e até um pouco irritado com a situação de entrevista.

Amedrontado: é igualmente um estilo de vinculação evitante, mas caracteriza-se mais pelo receio dos outros, ansiedade social e medo da rejeição ou de ser desiludido, que pode ser consequente de experiências passadas ou actuais que influenciam as atitudes do indivíduo. Elevado desejo de estar próximo dos outros e medo da proximidade podem coexistir. O estilo narrativo indica geralmente a ansiedade subjacente ao material emocional evocado.

Retraído: é uma categoria evitante residual, na qual se inserem traços de individualismo e falta de desejo de compromisso na relação com os outros, mas sem medo do envolvimento e sem cólera ou intolerância perante os outros.

Seguro: é um estilo de vinculação que se caracteriza pela competência em iniciar e manter relações interpessoais, tal como certifica a proximidade com o parceiro, os filhos e outras figuras de apoio fora da família. Existe geralmente um relacionamento estável, ou mesmo apoiante, com a família de origem. Atitudes extremas de hostilidade, dependência ou medo nas relações próximas são improváveis, embora evidências ligeiras possam estar presentes nos indivíduos classificados com um estilo de vinculação seguro.

$\mathrm{Na}$ avaliação da qualidade do suporte social e das relações interpessoais significativas, recorremos às versões para o parceiro e para outra pessoa significativa que se centra nos seguintes aspectos (6 subescalas): 'confiança', 'suporte emocional activo', 'sentimento de ligação/proximidade', 
'actividades partilhadas', 'qualidade da interacção positiva' e 'qualidade da interacção negativa'. A qualidade global do relacionamento estabelecido com cada pessoa em questão pode, ainda, ser classificada em: 1) muito boa; 2) média alta-discordante; 3 ) média alta-apática/indiferente; 4) média baixa-discordante; 5) média baixa-apática/indiferente; 6) pobre-discordante; 7) pobre-apática/indiferente. Os estudos psicométricos realizados com a versão portuguesa da $A S I$ demonstraram bons índices de fidelidade interobservadores e boa estabilidade na avaliação teste-reteste. Os níveis de concordância entre observadores variam entre 0,81 e 1,00 e as correlações entre as administrações pré-natal e pós-natal da $A S I$ variam entre 0,67 e 0,90 (Bifulco et al., 2004).

\section{Procedimentos}

Os registos das utentes foram consultados para proceder à selecção aleatória das participantes com tempo de gestação entre 24 e 36 semanas, as quais foram contactadas no dia da consulta médica. Nessa altura, foi prestada informação acerca da natureza e dos objectivos do estudo, solicitada a colaboração voluntária, garantida a confidencialidade e assegurado o consentimento informado.

As grávidas foram entrevistadas individualmente. As entrevistas foram transcritas e cotadas com base nos critérios definidos no manual, por avaliadores certificados na utilização do instrumento.

\section{Tratamentos Estatísticos}

No estudo do modo como características sociais e demográficas (idade, escolaridade, profissão, estatuto ocupacional, estatuto escolar, coabitação com o companheiro, coabitação com a família) e condições anteriores (antes dos 18 anos) de existência (paridade, morte de um ou de ambos os pais, separação ou divórcio parental, separação dos pais por mais de um ano) se relacionam com o estilo de vinculação da grávida, usámos o teste de qui-quadrado e a análise de regressão logística: o teste de qui-quadrado, para o estudo da associação entre características sociais e demográficas e condições adversas de existência e o estilo de vinculação da grávida (seguro versus inseguro, seguro versus emaranhado, seguro versus desligado e seguro versus amedrontado). A regressão logística, para determinar o peso das variáveis independentes (características sociais e demográficas e condições anteriores de existência) na predição do estilo de vinculação da grávida (seguro versus inseguro, seguro versus emaranhado, seguro versus desligado e seguro versus amedrontado).

A qualidade do relacionamento com o companheiro e com outra pessoa significativa foi analisada depois de dividida a amostra em grupos. 
Consideraram-se as participantes com: 1) melhor (muito bom/médio-alto) versus pior (médio-baixo/pobre) qualidade de relacionamento; 2) as participantes com relacionamento muito bom versus apático; e, 3) as participantes com relacionamento muito bom versus discordante. Recorremos a testes de qui-quadrado para testar a possibilidade de uma associação significativa entre o estilo de vinculação da grávida (seguro versus inseguro, emaranhado, desligado, amedrontado) e a qualidade do relacionamento com o companheiro e com outra pessoa significativa. Recorremos a análises de regressão logística, no sentido de identificar as variáveis, primeiro separadamente e depois conjuntamente, socio-demográficas, condições anteriores de existência e estilo de vinculação (seguro versus inseguro), passíveis de predizer a qualidade do relacionamento da grávida com figuras significativas.

Por último, analisamos as diferenças no relacionamento da grávida com o companheiro e com a outra figura significativa na presença de vinculação segura versus insegura, emaranhada, desligada e amedrontada, através de testes de qui-quadrado.

Dado o reduzido número de participantes com vinculação retraída, optou-se pela sua exclusão das análises estatísticas.

\section{Resultados}

Qualidade da vinculação na gravidez: características sociais e demográficas e condições anteriores de existência

No que se refere à qualidade da vinculação, observamos que a maior parte da amostra $(61,5 \%)$ apresenta um estilo de vinculação seguro, sendo, contudo, elevado o número de participantes com um estilo de vinculação inseguro $(38,5 \%)$. Quando consideramos os quatro estilos de vinculação insegura, concluímos que mais grávidas têm um estilo de vinculação emaranhado $(13,1 \%)$, seguindo-se o estilo de vinculação desligado $(12,3 \%)$, amedrontado $(10,8 \%)$ e retraído $(2,3 \%)$.

O primeiro objectivo deste estudo considera as características sociais e demográficas e as condições anteriores de existência que se associam e permitem prever um estilo de vinculação (in)seguro.

Vinculação segura versus insegura

Quanto às características sociais e demográficas, os resultados mostram que, no grupo com vinculação insegura, é superior ao que seria de esperar, numa distribuição ao acaso, o número de grávidas: com idade inferior ou igual a 18 anos $(35 / 50)\left(\chi^{2}(1)=12,022, \mathrm{p} \leq 0,01\right)$, desempregadas 
$(24 / 40)\left(\chi^{2}(1)=9,477, p \leq 0,01\right)$ e que não coabitam com o companheiro $(20 / 36)\left(\chi^{2}(1)=6,147, \mathrm{p} \leq 0,05\right)$.

No que concerne às condições anteriores de existência, os dados indicam que o grupo com vinculação insegura, em comparação ao grupo com vinculação segura, apresenta um maior número de grávidas: primíparas $(40 / 50)\left(\chi^{2}(1)=3,347, p=0,05\right)$, com divórcio ou separação parental $(20 / 50)$ $\left(\chi^{2}(1)=13,108, \mathrm{p} \leq 0,001\right)$ e com separação sem contacto dos pais por mais de um ano $(17 / 50)\left(\chi^{2}(1)=8,643, \mathrm{p} \leq 0,01\right)$ antes dos 18 anos de idade.

A análise de regressão logística que teve em conta as variáveis socio-demográficas revela um modelo estatisticamente quase significativo (qui-quadrado $=13,770, \mathrm{df}=7, \mathrm{p}=0,055$ ), em que o estatuto ocupacional da grávida é a variável que permite predizer o estilo de vinculação seguro versus inseguro, dado que grávidas desempregadas têm com maior frequência vinculação insegura ( $\mathrm{B}=-1,005, \mathrm{p}=0,040)$ (cf. Quadro 2).

A análise de regressão logística que considerou as condições anteriores de existência, também revela um modelo estatisticamente significativo (qui-quadrado $=17,709, \mathrm{df}=4, \mathrm{p}=0,001$ ), que tem agora como variável preditora do estilo de vinculação seguro versus inseguro a separação ou divórcio parental, sendo que a história de separação ou divórcio parental se associa ao estilo inseguro de vinculação da grávida $(B=1,005, p=0,047)$.

Quadro 2: Variáveis socio-demográficas e condições anteriores de existência na predição de vinculação segura versus insegura

\begin{tabular}{llrrrr}
\hline & & B & $\begin{array}{c}\text { Odds } \\
\text { Ratio }\end{array}$ & IC 95\% & p \\
\hline & idade & 0,023 & 1,023 & $0,948-1,104$ & 0,562 \\
& escolaridade & 0,242 & 1,274 & $0,749-2,165$ & 0,372 \\
& estatuto escolar & $-0,152$ & 0,859 & $0,222-3,320$ & 0,826 \\
& profissão & $-0,047$ & 0,954 & $0,670-1,361$ & 0,796 \\
Estilo de & estatuto ocupacional & $\mathbf{- 1 , 0 0 5}$ & $\mathbf{0 , 3 6 6}$ & $\mathbf{0 , 1 4 0 - 0 , 9 5 7}$ & $\mathbf{0 , 0 4 0}$ \\
vinculação & estado civil & $-0,408$ & 0,665 & $0,237-1,864$ & 0,438 \\
seguro & agregado familiar & $-0,309$ & 0,734 & $0,273-1,976$ & 0,541 \\
\cline { 2 - 6 } versus & paridade & $-0,432$ & 0,649 & $0,265-1,592$ & 0,345 \\
inseguro) & morte de um ou de ambos os pais & $-0,928$ & 0,395 & $0,091-1,724$ & 0,217 \\
& separação ou divórcio parental & $\mathbf{1 , 0 0 5}$ & $\mathbf{2 , 7 3 2}$ & $\mathbf{1 , 0 1 2 - 7 , 3 7 2}$ & $\mathbf{0 , 0 4 7}$ \\
& separação dos pais por mais de 1 ano & 0,934 & 2,546 & $0,899-7,205$ & 0,078 \\
\hline
\end{tabular}

Vinculação segura versus emaranhada, desligada e amedrontada

No grupo de grávidas com vinculação emaranhada, em relação ao grupo com vinculação segura, e no que se refere às características sociais e demográficas, o teste de qui-quadrado indica a presença de um maior número de indi- 
víduos com idade inferior ou igual a 18 anos $(13 / 17)\left(\chi^{2}(1)=8,049, \mathrm{p} \leq 0,01\right)$ e que não coabita com o companheiro $(8 / 17)\left(\chi^{2}(1)=5,513, \mathrm{p} \leq 0,05\right)$.

Quanto às condições anteriores de existência, os resultados mostram, no grupo de grávidas com vinculação emaranhada, em relação ao grupo com vinculação segura, um maior número de sujeitos com: divórcio ou separação parental $(7 / 17)\left(\chi^{2}(1)=7,977, p \leq 0,05\right)$ e separação dos pais sem contacto por mais de um ano $(7 / 17)\left(\chi^{2}(1)=7,977, p \leq 0,05\right)$, antes dos 18 anos de idade.

A análise de regressão logística que procurou identificar as variáveis socio-demográficas preditoras do estilo de vinculação seguro versus emaranhado revela um modelo que não explica melhor que o acaso o estilo de vinculação da grávida (qui-quadrado $=7,284, \mathrm{df}=7, \mathrm{p}=0,400$ ), não sendo identificada nenhuma variável preditora.

A análise de regressão logística que considerou as condições anteriores de existência na predição do estilo de vinculação seguro versus emaranhado, embora não identifique nenhuma variável preditora, dá conta de um modelo com significância marginal (qui-quadrado $=6,412, \mathrm{df}=4$, $\mathrm{p}=0,052)$.

No grupo de grávidas com vinculação desligada, em relação ao grupo com vinculação segura, o teste de qui-quadrado quanto às características sociais e demográficas indica uma sobre-representação de casos: com idade igual ou inferior a 18 anos $(13 / 16)\left(\chi^{2}(1)=9,701, \mathrm{p} \leq 0,01\right)$ e desempregados $(9 / 13)\left(\chi^{2}(1)=7,311, \mathrm{p} \leq 0,01\right)$.

No que concerne às experiências adversas de vida, o grupo de grávidas com vinculação desligada, em relação ao grupo com vinculação segura, apresenta mais divórcios ou separações parentais $(6 / 16)\left(\chi^{2}(1)=6,000\right.$, $\mathrm{p} \leq 0,05)$.

A análise de regressão logística que procurou identificar preditores do estilo de vinculação seguro versus desligado, entre as variáveis socio-demográficas em estudo, mostra um modelo estatisticamente significativo (qui-quadrado $=14,358, \mathrm{df}=7, \mathrm{p}=0,045)$, onde a idade é a variável que melhor prediz a vinculação segura/desligada, pois o facto de a grávida ter 18 ou menos anos de idade associa-se a um estilo desligado de vinculação $(B=0,174$, $\mathrm{p}=0,051)$.

A análise de regressão logística que considerou as condições anteriores de existência não evidencia, contudo, um modelo estatisticamente significativo (qui-quadrado $=9,118, \mathrm{df}=4, \mathrm{p}=0,058$ ), nem nenhuma variável preditora do estilo de vinculação seguro versus desligado da grávida.

No grupo de grávidas com vinculação amedrontada, comparado nas características sociais e demográficas ao grupo com vinculação segura, com recurso ao teste de qui-quadrado, existe um maior número de grávidas que não coabita com o companheiro $(7 / 14)\left(\chi^{2}(1)=5,802, p \leq 0,05\right)$. 
Em relação às condições anteriores de existência, o grupo de grávidas com vinculação amedrontada apresenta um maior número de casos de divórcio ou separação parental $(7 / 14)\left(\chi^{2}(1)=11,310, p \leq 0,01\right)$ e de separação sem contacto dos pais por mais de um ano $(6 / 8)\left(\chi^{2}(1)=7,774\right.$, $\mathrm{p} \leq 0,05)$, em relação ao grupo com vinculação segura.

A análise de regressão logística que, com base nas variáveis socio-demográficas em estudo, procurou identificar preditores para o estilo de vinculação seguro versus amedrontado, não revela um modelo estatisticamente significativo (qui-quadrado $=11,885, \mathrm{df}=7, \mathrm{p}=0,104$ ), nem nenhuma variável que permita predizer de forma significativa o estilo de vinculação da grávida.

No entanto, a análise de regressão logística que incluiu as condições anteriores de existência, mostra um modelo estatisticamente significativo (qui-quadrado $=11,668, \mathrm{df}=4, \mathrm{p}=0,020$ ), embora não seleccione nenhuma variável que separadamente possa predizer o estilo de vinculação seguro versus amedrontado.

Qualidade da vinculação na gravidez: impacto no relacionamento com o companheiro e com outra pessoa significativa

O segundo objectivo do presente estudo considera a importância do estilo de vinculação no quadro da explicação da qualidade do relacionamento com o companheiro e com outra pessoa significativa, na gravidez.

Qualidade do relacionamento com o companheiro

Muito bom / médio-alto versus médio-baixo / pobre

Quando se compara o grupo de grávidas com um relacionamento muito bom/médio-alto e o grupo com um relacionamento com o companheiro médio-baixo/pobre (cf. Quadro 3), verifica-se uma associação significativa entre a pertença ao grupo de grávidas com relacionamento médio-baixo/pobre e a presença de um estilo inseguro de vinculação, presente num maior número de participantes (17/49). Por sua vez, o grupo com um relacionamento muito bom/médio-alto tem mais grávidas com vinculação segura do que se poderia prever pelo acaso $(63 / 78)\left(\chi^{2}(1)=3,818, p \leq 0,05\right)$. Os estilos inseguros de vinculação que se associam a ter um relacionamento com o companheiro médio-baixo/pobre é o emaranhado (8/17) $\left(\chi^{2}(1)=5,891\right.$, $\mathrm{p} \leq 0,05)$ e o amedrontado $(7 / 14)\left(\chi^{2}(1)=6,176, p \leq 0,05\right)$, em contraponto ao estilo de vinculação seguro que, em ambos os casos, se associa a uma melhor relação com o companheiro. Não se verifica, contudo, uma associação significativa entre o estilo de vinculação desligado e um relacionamento muito bom/médio-alto versus médio-baixo/pobre da grávida com o companheiro $\left(\chi^{2}(1)=1,584, p>0,05\right)$ (cf. Quadro 3). 


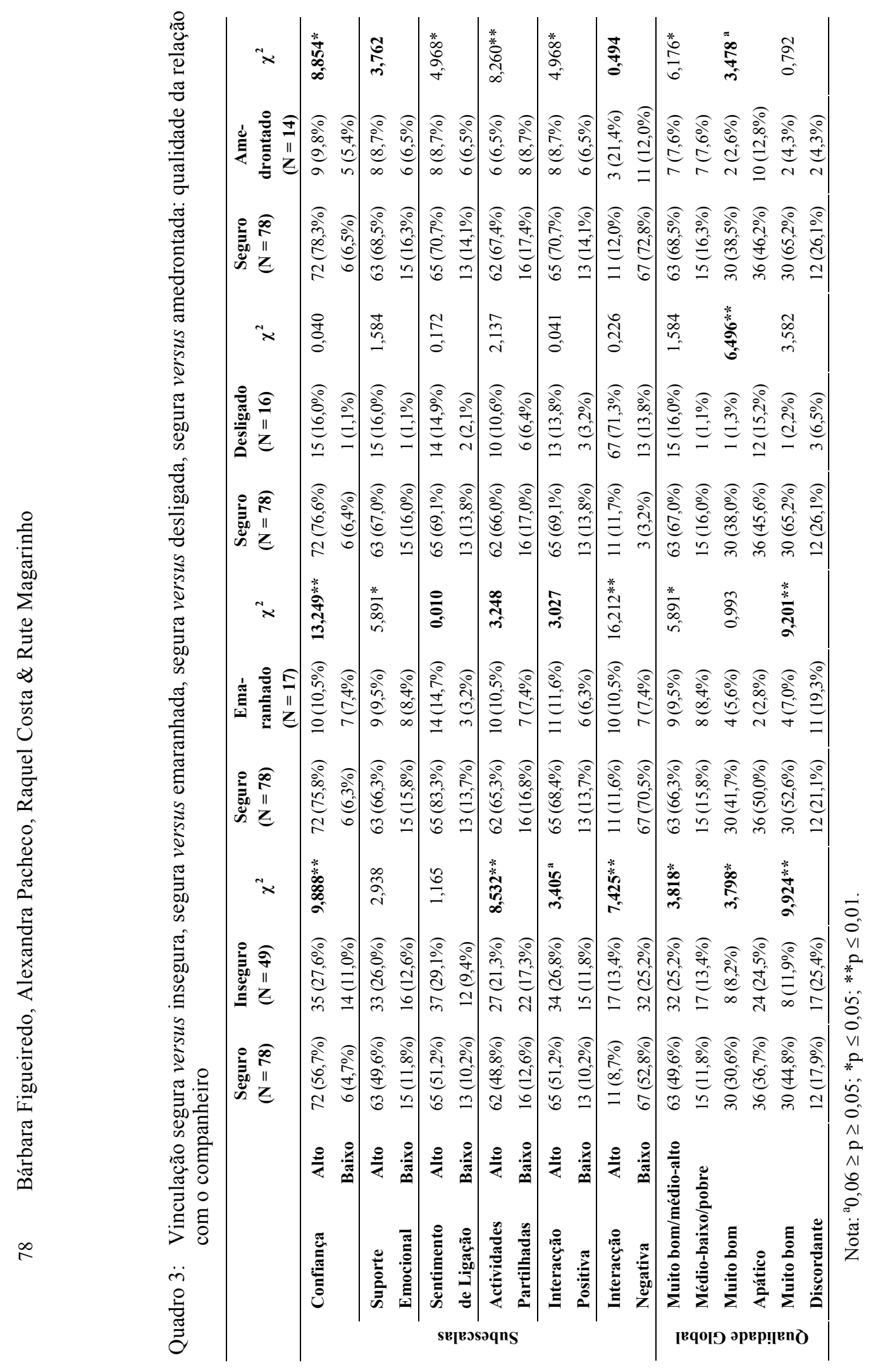


A análise de regressão logística que procurou identificar as variáveis socio-demográficas preditoras da qualidade do relacionamento com o companheiro evidencia um modelo estaticamente significativo (qui-quadrado $=20,352, \mathrm{df}=7, \mathrm{p}=0,005)$, em que a idade e a coabitação com o companheiro predizem um relacionamento muito bom/médio-alto versus médio-baixo/pobre, dado que participantes mais velhas $(\mathrm{B}=-0,163$, $\mathrm{p}=0,002)$ e que não coabitam com o companheiro $(\mathrm{B}=-2,239, \mathrm{p}=0,008)$ apresentam pior relacionamento com o companheiro.

Também a análise de regressão logística que considerou as condições anteriores de existência na predição da qualidade do relacionamento com o companheiro mostra um modelo estatisticamente significativo (qui-quadrado $=23,798, \mathrm{df}=4, \mathrm{p}=0,000$ ), onde a paridade prediz um relacionamento muito bom/médio-alto versus médio-baixo/pobre, pois as grávidas multíparas $(\mathrm{B}=1,412, \mathrm{p}=0,004)$ relacionam-se pior com o companheiro.

Procurou-se então averiguar quais as variáveis [condições sociodemográficas, circunstâncias anteriores de existência e estilo de vinculação (seguro versus inseguro)] com mais peso, para predizer a qualidade do relacionamento com o companheiro muito bom/médio-alto versus médio-baixo/pobre. Para tal realizou-se uma nova regressão logística para testar as variáveis significativamente relacionadas com os dois modelos anteriormente apresentados. Utilizou-se um critério de selecção das variáveis por excesso, em que escolhemos todas as variáveis com uma relação com o modelo de $\mathrm{p} \leq 0,15$. Neste caso, idade, escolaridade, coabitação com o companheiro e paridade. $\mathrm{O}$ estilo de vinculação foi igualmente considerado. Este modelo é mais eficaz que o acaso na predição da qualidade do relacionamento com o companheiro (qui-quadrado $=28,461, \quad \mathrm{df}=5$, $\mathrm{p}=0,000)$, sendo a idade, a coabitação com o companheiro e o estilo de vinculação as variáveis preditoras identificadas. A circunstância de a grávida ter maior idade $(B=-0,139, p=0,013)$, não coabitar com o companheiro $(B=-2,350, p=0,002)$ e ter um estilo inseguro de vinculação $(\mathrm{B}=-1,065, \mathrm{p}=0,035)$ associa-se a um pior relacionamento com o companheiro (médio-baixo/pobre).

\section{Muito bom versus apático}

Comprova-se que, no grupo com relacionamento apático com o companheiro, é superior ao que seria de esperar numa distribuição ao acaso o número de grávidas com vinculação insegura, em geral (24/49) $\left(\chi^{2}(1)=3,798, p \leq 0,05\right)$ e, particularmente, vinculação desligada $(12 / 13)$ $\left(\chi^{2}(1)=3,798, p \leq 0,01\right)$, quando se comparam, através do teste de qui-quadrado, os grupos com muito bom relacionamento e com relacionamento apático com o companheiro (cf. Quadro 3). 
Quadro 4: Variáveis socio-demográficas, condições anteriores de existência e estilo de vinculação na predição da qualidade do relacionamento com o companheiro

\begin{tabular}{|c|c|c|c|c|c|}
\hline & & B & $\begin{array}{l}\text { Odds } \\
\text { Ratio }\end{array}$ & IC 95\% & $\mathbf{p}$ \\
\hline \multirow{16}{*}{$\begin{array}{l}\text { muito bom } \\
\text { ou médio- } \\
\text {-alto } \\
\text { (versus } \\
\text { médio- } \\
\text {-baixo ou } \\
\text { pobre) }\end{array}$} & Idade & $\begin{array}{l}-0,163 \\
\end{array}$ & 0,850 & $0,766-0,944$ & 0,002 \\
\hline & escolaridade & 0,657 & 1,929 & $0,961-3,871$ & 0,065 \\
\hline & estatuto escolar & 0,319 & 1,375 & $0,257-7,351$ & 0,709 \\
\hline & profissão & 0,093 & 1,098 & $0,719-1,676$ & 0,666 \\
\hline & estatuto ocupacional & 0,344 & 1,411 & $0,413-4,826$ & 0,583 \\
\hline & estado civil & $-2,239$ & 0,107 & $0,020-0,555$ & 0,008 \\
\hline & agregado familiar & $-0,101$ & 0,904 & $0,265-3,086$ & 0,872 \\
\hline & paridade & 1,412 & 4,102 & $1,571-10,711$ & 0,004 \\
\hline & morte de um ou de ambos os pais & 0,866 & 2,378 & $0,623-9,077$ & 0,205 \\
\hline & separação ou divórcio parental & 0,665 & 1,944 & $0,584-6,473$ & 0,279 \\
\hline & separação dos pais por mais de 1 ano & 0,695 & 2,004 & $0,644-6,233$ & 0,230 \\
\hline & idade & $-0,139$ & 0,871 & $0,781-0,971$ & 0,013 \\
\hline & escolaridade & 0,574 & 1,775 & $0,916-3,441$ & 0,089 \\
\hline & estado civil & $-2,350$ & 0,095 & $\mathbf{0 , 0 2 2 - 0 , 4 1 7}$ & 0,002 \\
\hline & paridade & 1,091 & 2,977 & $0,759-11,671$ & 0,118 \\
\hline & estilo de vinculação & $-1,065$ & 0,345 & $0,128-0,926$ & $\mathbf{0 , 0 3 5}$ \\
\hline \multirow{23}{*}{$\begin{array}{l}\text { muito bom } \\
\text { (versus } \\
\text { apático) }\end{array}$} & idade & $-0,069$ & 0,933 & $0,850-1,025$ & 0,147 \\
\hline & escolaridade & 0,036 & 1,037 & $0,628-1,713$ & 0,888 \\
\hline & estatuto escolar & $-0,015$ & 0,985 & $0,232-4,176$ & 0,983 \\
\hline & profissão & $-0,027$ & 0,974 & $0,647-1,466$ & 0,899 \\
\hline & estatuto ocupacional & $-0,077$ & 0,926 & $0,275-3,120$ & 0,901 \\
\hline & estado civil & $-0,897$ & 0,408 & $0,104-1,594$ & 0,197 \\
\hline & agregado familiar & 0,177 & 1,193 & $0,429-3,316$ & 0,735 \\
\hline & paridade & $-0,292$ & 0,747 & $0,294-1,897$ & 0,539 \\
\hline & morte de um ou de ambos os pais & $-0,576$ & 0,562 & $0,129-2,449$ & 0,443 \\
\hline & separação ou divórcio parental & $-0,207$ & 0,813 & $0,220-3,008$ & 0,756 \\
\hline & separação dos pais por mais de 1 ano & 0,170 & 1,185 & $0,331-4,240$ & 0,794 \\
\hline & idade & $-0,178$ & 0,837 & $0,733-0,957$ & 0,009 \\
\hline & escolaridade & 0,058 & 1,060 & $0,615-1,827$ & 0,835 \\
\hline & estatuto escolar & $-0,040$ & 0,961 & $0,185-4,982$ & 0,962 \\
\hline & profissão & $-0,021$ & 0,980 & $0,624-1,538$ & 0,929 \\
\hline & estatuto ocupacional & $-0,112$ & 0,894 & $0,227-3,522$ & 0,873 \\
\hline & estado civil & $-0,440$ & 0,644 & $0,133-3,116$ & 0,584 \\
\hline & agregado familiar & 1,550 & 4,710 & $0,866-25,608$ & 0,073 \\
\hline & paridade & $-2,382$ & 0,092 & $0,013-0,664$ & 0,018 \\
\hline & morte de um ou de ambos os pais & $-0,756$ & 0,470 & $0,090-2,447$ & 0,369 \\
\hline & separação ou divórcio parental & $-0,385$ & 0,680 & $0,119-3,875$ & 0,664 \\
\hline & separação dos pais por mais de 1 ano & 0,054 & 1,055 & $0,215-5,188$ & 0,974 \\
\hline & estilo de vinculação & 0,894 & 2,445 & $0,764-7,832$ & 0,132 \\
\hline
\end{tabular}




\begin{tabular}{llcccc}
\hline & & B & $\begin{array}{c}\text { Odds } \\
\text { Ratio }\end{array}$ & IC 95\% & p \\
\hline & Idade & $-0,025$ & 0,976 & $0,877-1,086$ & 0,651 \\
& escolaridade & 1,204 & 3,332 & $0,705-15,737$ & 0,129 \\
& estatuto escolar & $-1,006$ & 0,366 & $0,027-5,008$ & 0,451 \\
& profissão & $-0,037$ & 0,964 & $0,580-1,603$ & 0,888 \\
& estatuto ocupacional & $-0,455$ & 0,634 & $-0,169-2,379$ & 0,500 \\
& estado civil & $-0,799$ & 0,450 & $0,096-2,102$ & 0,310 \\
muiton bom & agregado familiar & 0,443 & 1,558 & $0,383-6,336$ & 0,536 \\
\cline { 2 - 5 } (versus & maridade & 0,626 & 1,869 & $0,587-5,951$ & 0,290 \\
discor- & morte de um ou de ambos os pais & 1,192 & 3,294 & $0,674-16,101$ & 0,141 \\
dante) & separação ou divórcio parental & 1,546 & 4,693 & $1,078-20,436$ & 0,039 \\
& separação dos pais por mais de 1 ano & $-0,253$ & 0,777 & $0,184-3,271$ & 0,730 \\
\cline { 2 - 5 } & escolaridade & 1,009 & 3,000 & $0,725-12,412$ & 0,129 \\
& morte de um ou de ambos os pais & 0,911 & 2,487 & $0,494-12,528$ & 0,269 \\
& separação ou divórcio parental & 0,667 & 1,949 & $0,542-7,010$ & 0,307 \\
& estilo de vinculação & $-1,651$ & 0,192 & $0,060-0,618$ & 0,006 \\
\hline
\end{tabular}

A análise de regressão logística que procurou identificar variáveis socio-demográficas preditoras do relacionamento com o companheiro muito bom versus apático não encontra um modelo estatisticamente significativo (qui-quadrado $=3,863, \mathrm{df}=7, \mathrm{p}=0,795$ ), nem nenhuma variável que ultrapasse o limiar de significação estatística.

A análise de regressão logística que considerou as condições anteriores de existência na predição do relacionamento com o companheiro muito bom versus apático, também não revela significado estatístico (qui-quadrado $=0,919, \mathrm{df}=4, \mathrm{p}=0,922)$, nem identifica nenhuma variável que possa predizer a qualidade do relacionamento da grávida com o companheiro.

$\mathrm{Na}$ ausência de variáveis preditoras da qualidade do relacionamento com o companheiro muito bom versus apático, ao nível das variáveis socio-demográficas e das condições anteriores de existência analisadas em regressões separadas, optamos por testar a influência de todas as variáveis socio-demográficas e relativas a condições anteriores de existência, em conjunto com o estilo de vinculação da grávida (seguro versus inseguro). Este modelo não prediz melhor que o acaso a qualidade do relacionamento com o companheiro (qui-quadrado $=14,881, \mathrm{df}=12, \mathrm{p}=0,248$ ), porém identifica como preditores a idade e a paridade. A circunstância de a grávida ter maior idade $(B=-0,178, p=0,009)$ e ser primípara $(B=-2,382$, $\mathrm{p}=0,018$ ) associa-se a um relacionamento apático com o companheiro (cf. Quadro 4). 


\section{Muito bom versus discordante}

Considerando os grupos com um relacionamento com o companheiro muito bom versus discordante, observa-se um significativo maior número de casos com vinculação insegura $(17 / 49)\left(\chi^{2}(1)=9,924, p \leq 0,05\right)$, e com um estilo de vinculação emaranhado $(11 / 15)\left(\chi^{2}(1)=9,201, p \leq 0,01\right)$, no grupo de grávidas com relação discordante com o companheiro (cf. Quadro 3).

A análise de regressão logística que procurou identificar as variáveis socio-demográficas susceptíveis de predizer um relacionamento com o companheiro muito bom versus discordante, não encontra um modelo que explique melhor que o acaso a qualidade do relacionamento da grávida com o companheiro, nem nenhuma variável preditora da qualidade desse relacionamento.

A análise de regressão logística destinada a identificar as condições anteriores de existência preditoras da qualidade do relacionamento da grávida com o companheiro muito bom versus discordante também não encontra um modelo estatisticamente significativo (qui-quadrado $=6,037$, $\mathrm{df}=4, \mathrm{p}=0,196$ ), identifica porém como preditor a separação ou divórcio parental, que se associa a um relacionamento discordante com o companheiro $(B=1,546, p=0,039)$.

Procurou-se seguidamente averiguar, ao nível das variáveis socio-demográficas e das condições anteriores de existência, quais os preditores com mais peso para explicar a qualidade de relacionamento da grávida com o companheiro. Para tal, realizou-se uma nova regressão logística onde se testaram as variáveis que apresentaram uma relação significativa com os modelos anteriores, às quais se acrescentou o estilo de vinculação (seguro versus inseguro). Utilizou-se o mesmo critério de selecção das variáveis por excesso, em que foram escolhidas todas as variáveis que tinham uma relação com o modelo de $\mathrm{p} \leq 0,15$. Neste caso: escolaridade, morte de um ou de ambos os pais antes dos 18 anos, separação ou divórcio parental e estilo de vinculação. Este modelo mostra-se mais eficaz que o acaso para predizer a qualidade do relacionamento com o companheiro (qui-quadrado $=17,949, \mathrm{df}=4, \mathrm{p}=0,001)$, sendo o estilo de vinculação a variável preditora identificada. A circunstância de a grávida ter um estilo inseguro de vinculação $(\mathrm{B}=-1,651, \mathrm{p}=0,006)$ associa-se a um relacionamento discordante com o companheiro (cf. Quadro 4).

\section{Qualidade do relacionamento com outra pessoa significativa}

Mais de metade da amostra escolheu como pessoa "mais próxima" ou "em quem mais confia" (que não o companheiro) a sua própria mãe (56,6\%); as restantes grávidas nomearam a(o) irmã(o) (17,8\%), um(a) amigo(a) (9,3\%), um familiar do companheiro $(6,2 \%)$, uma outra pessoa $(5,4 \%)$, o próprio pai $(3,9 \%)$, ou ninguém $(0,8 \%)$. 


\section{Muito bom/médio-alto versus médio-baixo/pobre}

Quando se analisa, através do teste de qui-quadrado, os grupos com um relacionamento com a outra pessoa significativa muito bom/médio-alto e médio-baixo/pobre, verifica-se (cf. Quadro 5) um maior número de grávidas com um estilo inseguro de vinculação, no grupo com pior relacionamento (15/49), enquanto que, no grupo com melhor relacionamento, está presente um maior número de grávidas com vinculação segura $(75 / 78)$ $\left(\chi^{2}(1)=13,767, p \leq 0,001\right)$. Observa-se ainda uma associação específica entre o estilo inseguro de vinculação e o relacionamento com a outra pessoa significativa muito bom/médio-alto versus médio-baixo/pobre, dado a presença de um maior número de sujeitos com vinculação desligada $(6 / 16)\left(\chi^{2}(1)=12,834, p \leq 0,01\right)$ e com vinculação amedrontada $(6 / 14)$ $\left(\chi^{2}(1)=15,453, \mathrm{p} \leq 0,01\right)$, no grupo com um relacionamento médio-baixo/pobre com a outra pessoa significativa. No entanto, não se verifica uma associação significativa entre o estilo emaranhado de vinculação e a qualidade do relacionamento da grávida muito bom/médio-alto versus médio-baixo/pobre $\left(\chi^{2}(1)=2,727, p>0,05\right)$.

A análise de regressão logística que incluiu as variáveis socio-demográficas em estudo, na predição de um relacionamento com a outra pessoa significativa muito bom/médio-alto versus médio-baixo/pobre, não revela um modelo estatisticamente significativo (qui-quadrado $=8,085, \mathrm{df}=7, \mathrm{p}=0,325$ ), nem nenhuma variável que ultrapasse o limiar de significação estatística.

A análise de regressão logística, com vista a identificar as condições anteriores de existência preditoras de um relacionamento com a outra pessoa significativa muito bom/médio-alto versus médio-baixo/pobre, também não conduz a um modelo estatisticamente significativo (qui-quadra$\mathrm{do}=5,852, \mathrm{df}=4, \mathrm{p}=0,211)$, nem identifica nenhuma variável que ultrapasse o limiar de significação estatística.

$\mathrm{Na}$ ausência de variáveis preditoras da qualidade do relacionamento com a figura significativa muito bom/médio-alto versus médio-baixo/pobre, ao nível das variáveis socio-demográficas e das condições anteriores de existência, analisadas em regressões separadas, optamos por testar a influência de todas as variáveis socio-demográficas e relativas a condições anteriores de existência em conjunto com o estilo de vinculação da grávida (seguro versus inseguro). Este modelo mostra-se mais eficaz que o acaso e prediz a qualidade do relacionamento com a outra figura significativa (qui-quadrado $=13,670, \mathrm{df}=3, \mathrm{p}=0,003$ ), sendo o estilo de vinculação a variável preditora identificada: o facto de a grávida ter um estilo inseguro de vinculação $(\mathrm{B}=-1,733, \mathrm{p}=0,004)$ associa-se a um relacionamento médio-baixo/pobre com a outra figura significativa (cf. Quadro 6). 


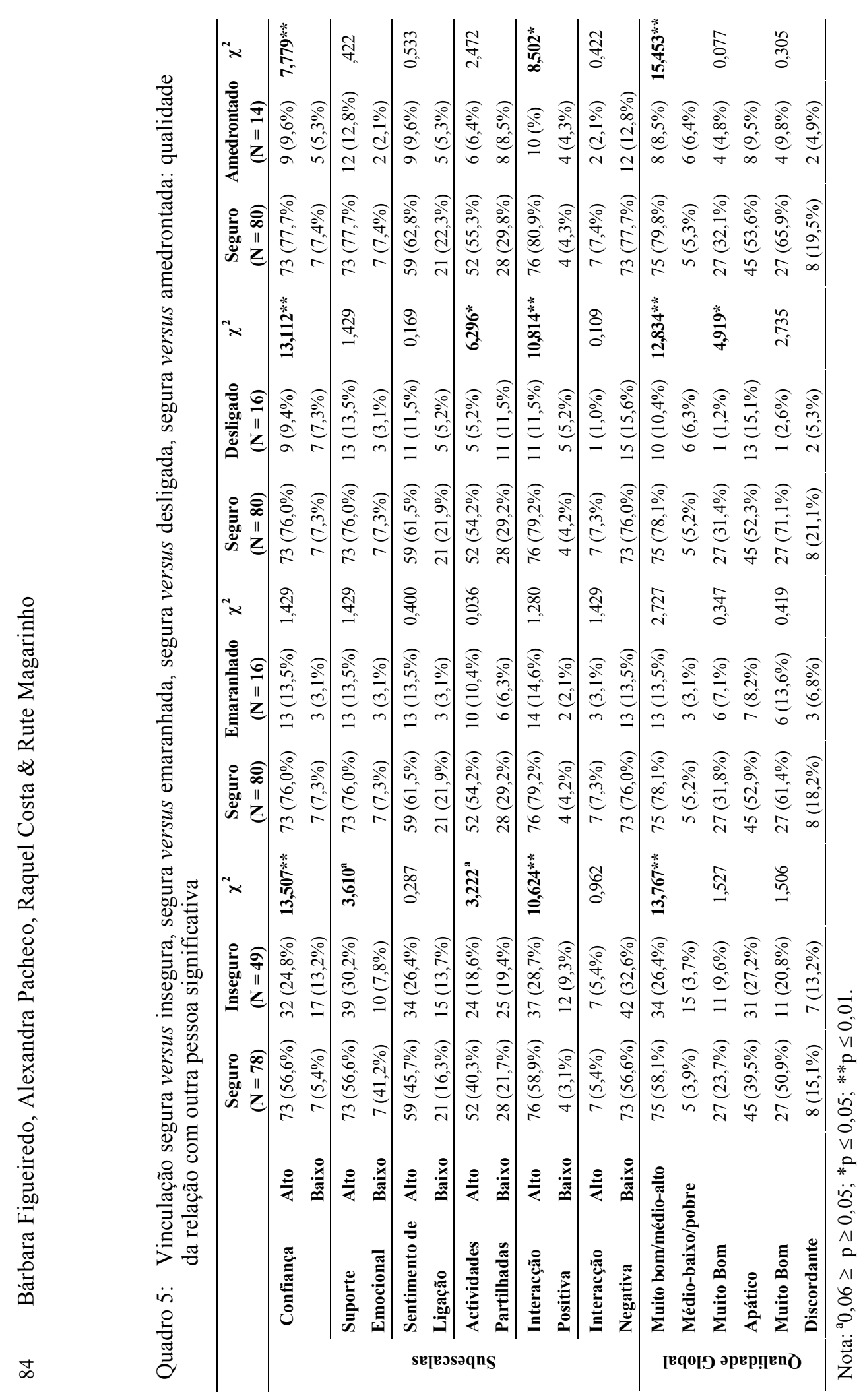


Quadro 6: Variáveis socio-demográficas, condições anteriores de existência e estilo de vinculação na predição da qualidade do relacionamento com outra pessoa significativa

\begin{tabular}{|c|c|c|c|c|c|}
\hline \multirow{14}{*}{$\begin{array}{l}\text { muito bom } \\
\text { ou médio- } \\
\text {-alto } \\
\text { (versus } \\
\text { médio-baixo } \\
\text { ou pobre) }\end{array}$} & Idade & $-0,042$ & 0,959 & $0,872-1,055$ & 0,388 \\
\hline & escolaridade & 0,446 & 1,562 & $0,728-3,351$ & 0,253 \\
\hline & estatuto escolar & $-0,522$ & 0,594 & $0,058-6,059$ & 0,660 \\
\hline & profissão & 0,013 & 1,013 & $0,643-1,595$ & 0,956 \\
\hline & promssao & $-1,026$ & 0,358 & $0,098-1,313$ & 0,121 \\
\hline & ocupacional & 1,099 & 3,002 & $0,526-17,137$ & 0,216 \\
\hline & $\begin{array}{l}\text { estado civil } \\
\text { agregado familiar }\end{array}$ & $-0,653$ & 0,521 & $0,162-1,676$ & 0,274 \\
\hline & paridade & 0,056 & 1,058 & $0,328-3,410$ & 0,925 \\
\hline & morte de um ou de ambos os pais & 0,055 & 1,056 & $0,194-5,750$ & 0,950 \\
\hline & senaracão ou divór & 0,558 & 1,748 & $0,507-6,023$ & 0,376 \\
\hline & separação dos pais por mais de 1 ano & 0,953 & 2,593 & $0,781-8,613$ & 0,120 \\
\hline & estatuto ocupacional & 0,410 & 1,507 & $0,480-4,727$ & 0,482 \\
\hline & separação dos pais por mais de 1 ano & 0,939 & 2,557 & $0,779-8,395$ & 0,122 \\
\hline & estilo de vinculação & $-1,733$ & 0,177 & $0,055-0,573$ & 0,004 \\
\hline \multirow{14}{*}{$\begin{array}{l}\text { muito bom } \\
\text { (versus } \\
\text { apático) }\end{array}$} & idade & $-\mathbf{0 , 1 3 8}$ & $\mathbf{0 , 8 7 1}$ & $0,783-0,969$ & 0,011 \\
\hline & escolaridade & $-0,153$ & 0,858 & $0,464-1,589$ & 0,627 \\
\hline & estatut & $-1,119$ & 0,327 & $0,070-1,527$ & 0,155 \\
\hline & profi & 0,261 & 1,299 & $0,853-1,978$ & 0,223 \\
\hline & pio & 0,107 & 1,113 & $0,352-3,519$ & 0,855 \\
\hline & estat & 0,702 & 2,018 & $0,607-6,715$ & 0,252 \\
\hline & $\begin{array}{l}\text { estado civil } \\
\text { agregado familiar }\end{array}$ & 0,601 & 1,824 & $0,566-5,878$ & 0,314 \\
\hline & paridade & 1,323 & 3,753 & $1,280-11,002$ & 0,016 \\
\hline & morte de um ou de ambos os pais & $-0,385$ & 0,680 & $0,167-2,77$ & 0,591 \\
\hline & separacão ou divórcio parental & $-0,303$ & 0,739 & $0,261-2,091$ & 0,568 \\
\hline & separação dos pais por mais de 1 ano & $-0,095$ & 0,910 & $0,301-2,753$ & 0,867 \\
\hline & idade & $-0,204$ & $\mathbf{0 , 8 1 5}$ & $0,737-0,902$ & $\mathbf{0 , 0 0 0}$ \\
\hline & paridade & $-0,078$ & 0,925 & $0,227-3,773$ & 0,914 \\
\hline & estilo de vinculação & $-1,480$ & 0,228 & $0,080-0,649$ & 0,006 \\
\hline \multirow{11}{*}{$\begin{array}{l}\text { muito bom } \\
\text { (versus } \\
\text { discordante) }\end{array}$} & idade & 0,009 & 1,009 & $0,840-1,210$ & 0,926 \\
\hline & escolaridade & 0,319 & 1,375 & $0,367-5,155$ & 0,636 \\
\hline & estatuto escolar & $-0,203$ & 0,816 & $0,100-6,646$ & 0,849 \\
\hline & & 0,108 & 1,115 & $0,591-2,101$ & 0,738 \\
\hline & piot & 0,674 & 1,962 & $0,262-14,689$ & 0,512 \\
\hline & estatuto ocupacional & 0,516 & 1,675 & $0,298-9,398$ & 0,558 \\
\hline & $\begin{array}{l}\text { estado civil } \\
\text { agregado familiar }\end{array}$ & 1,189 & 3,284 & $0,446-24,206$ & 0,243 \\
\hline & paridade & 0,926 & 2,525 & $0,487-13,088$ & 0,270 \\
\hline & morte de um ou de ambos os pais & 0,258 & 1,294 & $0,181-9,247$ & 0,797 \\
\hline & separação ou divórcio parental & $-0,523$ & 0,593 & $0,112-3,135$ & 0,538 \\
\hline & separação dos pais por mais de 1 ano & 0,562 & 1,754 & $0,376-8,184$ & 0,475 \\
\hline
\end{tabular}




\begin{tabular}{lcccc}
\hline idade & 0,014 & 1,014 & $0,798-1,290$ & 0,908 \\
escolaridade & 0,576 & 1,779 & $0,440-7,188$ & 0,419 \\
estatuto escolar & 0,234 & 1,263 & $0,092-17345$ & 0,861 \\
profissão & 0,329 & 1,389 & $0,644-2,996$ & 0,402 \\
estatuto ocupacional & 0,631 & 1,880 & $0,125-28,333$ & 0,648 \\
estado civil & 0,454 & 1,574 & $0,206-12,055$ & 0,662 \\
agregado familiar & 0,621 & 1,861 & $0,118-29,317$ & 0,659 \\
paridade & 1,337 & 3,806 & $0,144-100,263$ & 0,423 \\
morte de um ou de ambos os pais & 0,510 & 1,665 & $0,144-24,391$ & 0,710 \\
separação ou divórcio parental & $-2,202$ & 0,111 & $0,008-1,604$ & 0,107 \\
separação dos pais por mais de 1 ano & 0,723 & 2,062 & $0,195-21,757$ & 0,547 \\
estilo de vinculação & 1,504 & 4,498 & $0,580-34,917$ & 0,150 \\
\hline
\end{tabular}

\section{Muito bom versus apático}

Está presente uma associação entre o estilo de vinculação da grávida (seguro versus desligado) e a pertença aos grupos com um relacionamento com a outra pessoa significativa muito bom versus apático, dado que o teste de qui-quadrado mostra que as participantes com estilo desligado de vinculação têm mais frequentemente um relacionamento de tipo apático com a outra figura significativa $(13 / 14)\left(\chi^{2}(1)=4,919, \mathrm{p} \leq 0,01\right)$ (cf. Quadro 5).

A análise de regressão logística, conduzida no sentido de encontrar as variáveis socio-demográficas preditoras da qualidade do relacionamento da grávida com a outra pessoa significativa muito bom versus apático, revela um modelo estatisticamente significativo (qui-quadrado $=25,315$, $\mathrm{df}=7, \mathrm{p}=0,001$ ), onde a idade prediz a qualidade do relacionamento, nomeadamente porque as grávidas com maior idade apresentam mais um relacionamento apático com a outra figura significativa $(B=-0,138$, $\mathrm{p}=0,011)$.

Por sua vez, a análise de regressão logística que procurou identificar as condições anteriores de existência preditoras de um relacionamento com a outra pessoa significativa muito bom versus apático, embora mostre um modelo com significância estatística marginal (qui-quadrado $=9,067$, $\mathrm{df}=4, \mathrm{p}=0,059)$, identifica a paridade como preditora da qualidade do relacionamento da grávida, dado que as participantes multíparas revelam com maior frequência um relacionamento de tipo apático com a outra pessoa significativa $(B=1,323, p=0,016)$.

Procurou-se então analisar que variáveis teriam maior peso para predizer um relacionamento muito bom versus apático da grávida com a outra figura significativa, através de uma nova regressão logística onde se testaram as variáveis que apresentaram uma relação significativa com os dois modelos apresentados anteriormente, às quais se juntou o estilo de vinculação (seguro versus inseguro). Utilizou-se o mesmo critério de selecção das 
variáveis por excesso, em que todas as variáveis que apresentavam uma relação com o modelo de $\mathrm{p} \leq 0,15$ foram escolhidas, especificamente: idade, paridade e estilo de vinculação. Este modelo mostra-se mais eficaz que o acaso na predição da qualidade do relacionamento apático com a outra pessoa significativa (qui-quadrado $=33,010, \mathrm{df}=3, \mathrm{p}=0,000$ ), sendo a idade e o estilo de vinculação as variáveis preditoras identificadas. A circunstância de a grávida ter maior idade $(B=-0,204, p=0,000)$ e ter um estilo inseguro de vinculação $(B=-1,480, p=0,006)$ associa-se a um relacionamento apático com a outra figura significativa (cf. Quadro 6).

\section{Muito bom versus discordante}

Não se encontram associações estatisticamente significativas entre o estilo de vinculação da grávida e a qualidade do relacionamento com a outra pessoa significativa muito bom versus discordante (cf. Quadro 5).

A análise de regressão logística que considerou as variáveis socio-demográficas na predição da qualidade do relacionamento da grávida com a outra figura significativa muito bom versus discordante também não revela um modelo estatisticamente significativo (qui-quadrado $=2,380$, $\mathrm{df}=7, \mathrm{p}=0,936$ ), ou alguma variável que ultrapasse o limiar de significação estatística.

Do mesmo modo, quando foram incluídas as condições anteriores de existência da grávida, a análise de regressão logística não revela um modelo estatisticamente significativo do relacionamento com a outra figura significativa muito bom/discordante (qui-quadrado $=2,239, \mathrm{df}=4$, $\mathrm{p}=0,692$ ), nem encontra nenhuma variável que ultrapasse o limiar de significação estatística.

$\mathrm{Na}$ ausência de variáveis preditoras da qualidade do relacionamento com a outra figura muito bom/discordante, ao nível das variáveis socio-demográficas e das condições anteriores de existência analisadas em regressões separadas, testámos a influência do conjunto destas variáveis e do estilo de vinculação da grávida (seguro versus inseguro). Contudo, este modelo também não prediz melhor que o acaso a qualidade do relacionamento com a outra pessoa significativa (qui-quadrado $=9,190, \mathrm{df}=12$, $\mathrm{p}=0,687)$, nem identifica nenhuma variável preditora da qualidade do relacionamento com a mesma (cf. Quadro 6).

Qualidade da vinculação na gravidez: descrição das estratégias de relacionamento com o companheiro e com outra pessoa significativa

Procurámos, por último, testar as diferenças na qualidade das relações significativas das participantes com diferentes estilos de vinculação, com vista a melhor responder ao segundo objectivo do presente estudo e 
encontrar o sentido e as áreas do relacionamento com o companheiro e com outra pessoa significativa afectadas pelo estilo (in)seguro de vinculação da grávida (cf. Quadros 3 e 5).

No que diz respeito à qualidade do relacionamento com o companheiro, em comparação com o grupo de grávidas com vinculação segura, verifica-se que, no grupo de grávidas com vinculação insegura, é superior ao que seria de esperar numa distribuição ao acaso o número de sujeitos com: baixa confiança $(14 / 49)\left(\chi^{2}(1)=9,888, p=0,002\right)$, poucas actividades partilhadas $(22 / 49)\left(\chi^{2}(1)=8,532, p=0,003\right)$, pouca interacção positiva $(15 / 49) \quad\left(\chi^{2}(1)=3,405, p=0,053\right)$, mais interacção negativa $(17 / 49)$ $\left(\chi^{2}(1)=7,425, p=0,007\right)$, relacionamento médio-baixo/pobre $(17 / 49)$ $\left(\chi^{2}(1)=3,818, p=0,041\right)$, relacionamento apático $(24 / 32)\left(\chi^{2}(1)=3,798\right.$, $\mathrm{p}=0,040)$ e relacionamento discordante $(17 / 25)\left(\chi^{2}(1)=9,924, \mathrm{p}=0,002\right)$. Quando se analisa a qualidade do relacionamento com a outra figura significativa, também se encontram diferenças entre o grupo com vinculação segura e o grupo com vinculação insegura, onde está presente um maior número de grávidas com: baixa confiança $(17 / 49)\left(\chi^{2}(1)=13,507, p=0,000\right)$, baixo suporte emocional $(10 / 49)\left(\chi^{2}(1)=3,610, p=0,053\right)$, poucas actividades partilhadas $(25 / 49)\left(\chi^{2}(1)=3,222, p=0,054\right)$, pouca interacção positiva $(12 / 49)\left(\chi^{2}(1)=10,624, \mathrm{p}=0,002\right)$ e relacionamento médio-baixo/pobre $(15 / 49)\left(\chi^{2}(1)=13,767, \mathrm{p}=0,000\right)$.

Comparando o grupo com vinculação segura e o grupo com vinculação emaranhada, surgem diferenças significativas no relacionamento com o companheiro, pois o grupo com vinculação emaranhada tem significativamente mais elementos com: baixa confiança $(7 / 17)\left(\chi^{2}(1)=13,249\right.$, $\mathrm{p}=0,002)$, baixo suporte emocional $(8 / 17)\left(\chi^{2}(1)=5,891, \mathrm{p}=0,021\right)$, elevada interacção negativa $(10 / 17)\left(\chi^{2}(1)=16,212, p=0,000\right)$, pior relacionamento (médio-baixo/pobre) $(8 / 17)\left(\chi^{2}(1)=5,891, \mathrm{p}=0,021\right)$ e relacionamento discordante com o companheiro $(11 / 15)\left(\chi^{2}(1)=9,201, p=0,003\right)$. No entanto, não se verifica que o grupo com vinculação emaranhada se distinga significativamente do grupo com vinculação segura, em nenhuma das dimensões consideradas para a qualidade do relacionamento com a outra figura significativa.

Embora não se verifiquem diferenças significativas na relação com o companheiro entre os grupos com vinculação segura e desligada, em nenhuma das subescalas, a presença de um significativo maior número de grávidas com vinculação desligada e um relacionamento apático com o companheiro $(12 / 13)\left(\chi^{2}(1)=6,496, p=0,009\right)$ foi constatada. Os resultados mostram-se ainda estatisticamente significativos para diversos aspectos da qualidade do relacionamento com a outra figura significativa, pois um número superior ao que seria de esperar, numa distribuição ao acaso, 
de participantes com vinculação desligada (em relação ao grupo com vinculação segura) tem: baixa confiança $(7 / 16)\left(\chi^{2}(1)=13,112, p=0,002\right)$, poucas actividades partilhadas $(11 / 16)\left(\chi^{2}(1)=6,296, \mathrm{p}=0,013\right)$, pouca interacção positiva $(5 / 16)\left(\chi^{2}(1)=10,814, p=0,006\right)$, pior relacionamento (médio-baixo/pobre) $(6 / 16)\left(\chi^{2}(1)=12,834, \mathrm{p}=0,002\right)$ e relacionamento apático $(13 / 14)\left(\chi^{2}(1)=4,919, \mathrm{p}=0,022\right)$

No que concerne ao grupo com vinculação amedrontada, os resultados indicam a presença de diferenças significativas no relacionamento com o companheiro, já que tem significativamente mais sujeitos com: baixa confiança $(5 / 14)\left(\chi^{2}(1)=8,854, p=0,011\right)$, fraco sentimento de ligação $(6 / 14)\left(\chi^{2}(1)=4,968, p=0,037\right)$, poucas actividades partilhadas $(8 / 14)$ $\left(\chi^{2}(1)=8,260, p=0,008\right)$, pouca interacção positiva $(6 / 14)\left(\chi^{2}(1)=4,968\right.$, $\mathrm{p}=0,037)$, pior relacionamento (médio-baixo/pobre) $(7 / 14)\left(\chi^{2}(1)=6,176\right.$, $\mathrm{p}=0,020)$ e relacionamento apático $(10 / 12)\left(\chi^{2}(1)=3,478, \mathrm{p}=0,057\right)$, do que no grupo com vinculação segura. Os resultados revelam mais diferenças significativas, mas agora para a qualidade do relacionamento com a outra figura significativa, pois, comparativamente ao grupo com vinculação segura, o grupo com vinculação amedrontada apresenta um maior número de participantes com: baixa confiança $(5 / 14)\left(\chi^{2}(1)=7,779, \mathrm{p}=0,015\right)$, pouca interacção positiva $(4 / 14)\left(\chi^{2}(1)=8,502, \mathrm{p}=0,016\right)$ e pior relacionamento (médio-baixo/pobre) $(6 / 14)\left(\chi^{2}(1)=15,453, p=0,001\right)$.

\section{Discussão dos Resultados e Conclusão}

1. Antes de passarmos à discussão mais detalhada dos resultados, importa assinalar que, embora a maioria das participantes no estudo apresente vinculação segura, é elevado o número de sujeitos com vinculação insegura $(38,5 \%)$. Tendo em conta que parte da amostra é constituída por grávidas adolescentes, justifica-se que a proporção de sujeitos com vinculação insegura seja ligeiramente superior ao verificado em outras amostras de grávidas com recurso ao mesmo instrumento, nomeadamente em Portugal (31\%) (Bifulco et al., 2004). No entanto, a percentagem de indivíduos com vinculação insegura no nosso estudo está dentro dos limites inferiores dos valores geralmente obtidos com recurso a medidas de auto-relato, em amostra de adultos (Shaver \& Hazan, 1993, para uma revisão) ou de grávidas (Besser et al., 2002), ou com recurso à Adult Attachment Interview em amostra de adolescentes ou adultos (van Ijzendoorn \& Bakermans-Kranenburg, 1996, para uma revisão).

2. O estudo descrito neste artigo considera como primeiro objectivo encontrar as variáveis sociais e demográficas e as condições anteriores de 
existência que se relacionam ou permitem predizer a qualidade da vinculação na gravidez.

Verifica-se uma associação significativa entre a ocorrência de vinculação insegura e, quer de características sociais e demográficas - ser adolescente, estar desempregada e não viver com o pai do bebé -, quer de condições anteriores de existência - ser primípara, ter vivido o divórcio ou separação parental e ter estado separada dos pais, por mais de um ano, sem contacto antes da idade de 18 anos. Mais, mostra que é possível prever um estilo de vinculação inseguro na sequência de divórcio ou separação parental, durante a infância ou adolescência. $\mathrm{O}$ modelo que considera condições sociais e demográficas na predição da qualidade da vinculação selecciona, por sua vez, o estatuto ocupacional e mostra que o facto de a grávida estar desocupada se associa a um estilo inseguro de vinculação.

Quando consideramos especificamente o tipo de estilo inseguro de vinculação da grávida, observamos que um estilo emaranhado se associa ao facto de ter idade igual ou inferior a 18 anos e não viver com o pai do bebé, assim como ter vivido o divórcio ou a separação parental ou separação dos pais, sem contacto, por mais de 1 ano, durante a infância ou adolescência. Enquanto isso, o estilo desligado, embora também se associe à menor idade, apresenta uma associação apenas com a separação ou divórcio parental, e agora também com o facto de a grávida estar desempregada. Tal parece sugerir uma matriz algo distinta, quer no que concerne às circunstâncias da infância (divórcio parental versus separação dos pais) que podem ser de risco para a construção de determinadas estratégias inseguras de vinculação, quer quanto aos problemas específicos (conflitos versus desinvestimento) que determinadas estratégias inseguras de vinculação podem implicar para o indivíduo, na adaptação a diferentes tarefas de vida, o que, a nosso ver, é uma pista relevante para investigação futura. O número reduzido de indivíduos na amostra em estudo, com cada uma das classificações de vinculação insegura previstas na $A S I$, não permitiu testar com eficácia os modelos de previsão propostos, mas os resultados sugerem, contudo, a pertinência dos mesmos. Nomeadamente porque, mesmo assim, foi possível prever um estilo emaranhado e um estilo amedrontado com base nas experiências adversas durante a infância ou adolescência e um estilo desligado, no caso de a grávida ser adolescente.

Podemos, assim, concluir que, como prevíamos e é descrito na literatura, acontecimentos de vida adversos durante a infância ou adolescência, predispõem a um estilo de vinculação inseguro (Beckwith et al., 1999; Mickelson et al., 1997). Na conclusão do seu estudo, Beckwith et al. (1999) salientam que determinadas circunstâncias até aos 12 anos de idade, particularmente o divórcio parental, reduzem a probabilidade de representação segura e aumentam a probabilidade de representação preocupada na 
idade adulta, à semelhança do que foi por nós verificado. Embora a maior parte da literatura tenha privilegiado a análise do efeito do abuso e negligência na emergência de estratégias inseguras de vinculação, os nossos resultados estão em conformidade com mais estudos que verificam uma associação entre experiências, durante a infância, de separação/divórcio parental (Beckwith et al., 1999; Mickelson et al., 1997) e de separação prolongada em relação à mãe (Feeney \& Noller, 1990) e estilo inseguro de vinculação, assim como um elevado número de sujeitos desligados em amostras de mães adolescentes (Ward \& Carlson, 1995). Um estilo de vinculação inseguro associa-se também a condições de existência actuais menos favoráveis e resulta em pior adaptação social, tal como testemunha, por exemplo, a circunstância de a grávida estar desocupada, e foi também observado por outros autores (e.g., Bifulco et al., 2004).

Convém, no entanto, assinalar que a presente investigação não se refere a uma amostra representativa, mais precisamente por incluir um número elevado de grávidas adolescentes, o que beneficiou a presença de maior variabilidade e incidência aumentada de circunstâncias adversas de existência, mas forçou a importância de determinados preditores, o que é uma limitação do estudo e obriga a interpretação e generalização cautelosas dos resultados.

3. Com o segundo objectivo pretendíamos verificar até que ponto o estilo de vinculação interfere na qualidade do relacionamento da grávida com o companheiro e com uma outra pessoa significativa.

Nesse sentido, verificamos que um estilo inseguro de vinculação, mais especificamente um estilo de vinculação emaranhado e amedrontado, se associa a um relacionamento médio-baixo/pobre com o companheiro. Para além disso, o estilo de vinculação mostrou ser um preditor significativo da qualidade do relacionamento com o companheiro, quando considerado em conjunto com variáveis socio-demográficas e condições anteriores de existência, já que a circunstância de a grávida ter um estilo inseguro de vinculação, ter maior idade e não viver com o companheiro se associa a um pior relacionamento com o companheiro.

Constatamos que o estilo inseguro de vinculação se associa também ao pior relacionamento com a outra pessoa significativa, mas agora, mais especificamente, o estilo de vinculação desligado e amedrontado. E verificamos ainda que o estilo de vinculação é o único preditor significativo do melhor ou pior relacionamento da grávida com a outra pessoa significativa, quando considerado em conjunto com as condições socio-demográficas e as circunstâncias anteriores de existência em estudo.

No que concerne ao relacionamento apático com o companheiro, a presença de uma associação com a vinculação insegura (mais especifica- 
mente com o estilo desligado) foi observada. O estilo de vinculação não mostra, contudo, ser um preditor significativo do relacionamento apático com o companheiro, quando considerado em conjunto com as condições socio-demográficas e circunstâncias anteriores de existência, dado que a idade e a paridade foram os únicos preditores identificados (ter maior idade e ser primípara associa-se a um relacionamento apático com o companheiro). No entanto, o estilo de vinculação é preditor significativo da qualidade do relacionamento muito bom versus apático com a outra pessoa significativa, em conjunto com a idade, dado que as grávidas de maior idade e com estilo inseguro de vinculação tendem mais a ter um relacionamento apático com a outra pessoa significativa.

A presença de uma associação entre relacionamento discordante com o companheiro e estilo inseguro de vinculação (mais especificamente estilo emaranhado) foi também constatada. Mais, o estilo inseguro de vinculação mostrou ser o único preditor significativo da presença de um relacionamento discordante com o companheiro. Contudo, nenhuma das variáveis consideradas no estudo, inclusive o estilo de vinculação, foi susceptível de predizer o relacionamento discordante com a outra pessoa significativa.

Assim, em conformidade com a literatura, os resultados comprovam e permitem concluir o impacto do estilo de vinculação na qualidade dos relacionamentos significativos (companheiro e outra pessoa) do indivíduo (e.g., Brennan \& Shaver, 1995; Eiden et al., 1995; Feeney \& Noller, 1991; Hazan \& Shaver, 1987; Koback \& Hazan, 1991; Levy \& Davis, 1988; Pacheco et al., 2003; Simpson, 1990). Documentam ainda as dimensões específicas que são mais afectadas pelas diferentes estratégias inseguras de vinculação da grávida. A investigação assinalou que menor satisfação, menor ajustamento e mais conflitos são reportados no relacionamento com o companheiro, sobretudo pelos sujeitos com um estilo inseguro preocupado/ambivalente (e.g., Feeney \& Noller, 1990; Feeney et al., 1994; Kickpatrick \& Hazan, 1994; McCarthy \& Taylor, 1999; Rholes et al., 2001). À semelhança do que foi observado por esses autores, verificámos que as estratégias emaranhadas suscitam sobretudo conflitos, enquanto que as estratégias desligadas resultam mais em apatia no relacionamento com o companheiro. Os resultados permitem ainda concluir que as mulheres com vinculação insegura e com mais idade (ou sobretudo quando têm maior idade) estão mais em risco de relações menos favoráveis com o companheiro e com a outra pessoa significativa durante a gravidez, que as torna particularmente vulneráveis à depressão (Figueiredo, Bifulco, Pacheco, Costa \& Magarinho, submitted).

Convém, contudo, ressalvar que o estudo não avalia o impacto que a qualidade do relacionamento actual, nomeadamente com o companheiro, pode ter sobre o estilo de vinculação da grávida, já que "os working 
models podem ser revistos com base na experiência por ocasião de relacionamentos íntimos" (Feeney, 1999, p. 367), nem tão-pouco o impacto do estilo de vinculação do companheiro sobre a qualidade do relacionamento relatada pela grávida.

4. Na linha do que acabámos de concluir, são ainda particularmente esclarecedores e estão em sintonia com a literatura actual sobre o tema os dados do nosso estudo que se referem à associação entre diferentes estratégias inseguras de vinculação e cada uma das dimensões avaliadas no relacionamento com o companheiro e com a outra pessoa significativa.

Assim, é interessante salientar que quase todos os estilos inseguros de vinculação se associam a baixa confiança. Excepção para as grávidas com estilo emaranhado, no relacionamento com o outro significativo, e nas grávidas com estilo desligado, no relacionamento com o parceiro. Por sua vez, o estilo emaranhado associa-se a baixo suporte emocional no relacionamento com o parceiro. O estilo desligado, na relação com o outro significativo, e o estilo amedrontado, na relação com o parceiro, associam-se à presença de poucas actividades partilhadas. $\mathrm{O}$ estilo desligado, na relação com o outro significativo, e o estilo amedrontado, na relação com o parceiro, relacionam-se com pouca interacção positiva. As grávidas emaranhadas apresentam mais interacção negativa na relação com o parceiro. Os estilos emaranhado e amedrontado caracterizam-se por um pior relacionamento com o parceiro, enquanto que os estilos desligado e amedrontado se associam a um pior relacionamento com o outro significativo. $\mathrm{O}$ estilo desligado associa-se ao relacionamento apático, quer com o companheiro, quer com a outra pessoa significativa. Um estilo de vinculação emaranhado relaciona-se com um relacionamento discordante, mas exclusivamente na relação com o companheiro. Parece-nos ainda relevante acrescentar que o estilo de vinculação emaranhado não parece afectar negativamente nenhuma das dimensões avaliadas do relacionamento da grávida com a outra pessoa significativa, enquanto que o estilo desligado, embora se associe a um relacionamento apático, também não parece afectar nenhuma das dimensões avaliadas do relacionamento da grávida com o parceiro, em conformidade com os resultados de outros autores que referem que as estratégias evitantes podem não afectar tão significativamente o relacionamento com o companheiro (e.g., Rholes et al., 2001).

Conhecer melhor a forma como estratégias inseguras de vinculação, embora se traduzam em maior dificuldade e menor ajustamento no relacionamento interpessoal, podem não excluir a possibilidade de o indivíduo beneficiar de relações adaptadas, em contextos ou com pessoas específicas, revela ser uma interessante área de investigação, com importantes implicações a nível clínico. 


\section{Referências}

Alexander, P. C. (1992). Application of attachment theory to the study of sexual abuse. Journal of Consulting and Clinical Psychology, 60 (2), 185-95.

Ammaniti, M., Baumgartner, E., Candelori, C., Perucchini, P., Pola, M., Tambelli, R., \& Zampino, F. (1992). Representations and narratives during pregnancy. Infant Mental Health Journal, 13 (2), 167-182.

Bartholomew, K., \& Horowitz, L. M. (1991). Attachment styles among young adults: A test of a four-category model. Journal of Personality and Social Psychology, 61 (2), 226-244.

Beckwith, L., Cohen, S., \& Hamilton, C. E. (1999). Maternal sensitivity during infancy and subsequent life events related to attachment representation at early adulthood. Developmental Psychology, 35 (3), 693-672.

Belsky, J., Rovine, M., \& Fish, M. (1989). The developing family system. In M. R. Gunnar \& E. Thelen, (Eds.), Systems and development. The Minnesota symposia on child psychology, (vol. 22, pp. 119-166). Hillsdale: Lawrence Erlbaum Associates.

Besser, A., Priel, B., \& Wiznitzer, A. (2002). Childbearing depressive symptomatology in high-risk pregnancies: The roles of working models and social support. Personal Relationships, 9 (4), 395-413.

Bifulco, A., Figueiredo, B., Guedeney, N., Gorman, L., Hayes, S., Muzik, M, Glatigny-Dallay E., Valoriani, V., Kammerer, M., Henshaw, C. \& TCS-PND group (2004). Maternal attachment style and depression associated with childbirth: Preliminary results from a European and US cross-cultural study of postnatal depression. British Journal of Psychiatry, 184, (Suppl. 46), 33-40.

Bifulco, A., Moran, P. M., Ball, C., \& Bernazzani, O. (2002a). Adult attachment style I: Its relationship to clinical depression. Social Psychiatry \& Psychiatric Epidemiology, 37 (2), 50-59.

Bifulco, A., Moran, P. M., Ball, C., \& Lillie, A. (2002b). Adult attachment style II: Its relationship to psychosocial depressive-vulnerability. Social Psychiatry \& Psychiatric Epidemiology, 37 (2), 60-67.

Bifulco, A., Lillie, A., Ball, B., \& Moran, P. (1988). Entrevista de estilos de vinculação (A.S.I.): Manual de treino; versão 2 (reduzida). Royal Holloway: Universidade de Londres.

Bowlby, J. (1973). Attachment and loss. Vol. 2: Separation: Anxiety and anger. New York: Basic Books.

Bowlby, J. (1988). A Secure Base: Parent-Child Attachment and Healthy Human Development. Basic Books.

Brennan, K. A., \& Shaver, P. (1995) Dimensions of adult attachment, affect regulation, and romantic relationship functioning. Personality and Social Psychology Bulletin, 21 (3), 267-284.

Cozzarelli, C., Karafa, J., Collins, N., \& Tagler, M. J. (2003). Stability and change in adult attachment styles: Associations with personal vulnerabilities, life events, and global construals of self and others. Journal of Social \& Clinical Psychology, 22 (3), 315-346. 
Eiden, R., Teti, D. M., \& Corns, K. M. (1995). Maternal working models of attachment, marital adjustment, and the parent-child relationship. Child Development, 66, 1504-1518.

Feeney, J. A., \& Noller, P. (1991). Attachment style and verbal descriptions of romantic partners. Journal of Social and Personal Relationships, 8, 187-215.

Feeney, J., Alexander, R., Noller, P., \& Hohaus, L. (2003). Attachment insecurity, depression, and the transition to parenthood. Personal Relationships, 10 (4), 475-493.

Feeney, L., Dempsey, J., Moynihan, F., Barry, S. (2003). Changes in body mass indices of patients with schizophrenia 3 years following the introduction of a weight management programme. Irish Medical Journal, 96 (9), 276-277.

Feeney, J. A. (1999). Adult romantic attachment and couple relationships. In J. Cassidy \& P. R. Shaver (Eds.), Handbook of Attachment (pp. 355-377). New York: Guilford.

Feeney, J. A., \& Noller, P. (1990). Attachment styles as a predictor of adult romantic relationships. Journal of Personality and Social Psychology, 58 (2), 281-291 .

Feeney, J. A., Noller, P., \& Callan, V. J. (1994). Attachment style, communication and satisfaction in the early years of marriage. Advances in Personal Relationships, 5, 269308.

Figueiredo, B. (2005). Psicopatologia da Maternidade e Paternidade. In I. Lança (Coord.), Estudos e Ensaios em Homenagem a Eurico Figueiredo (pp. 83-102). Porto: Edições Afrontamento \& CEPESE.

Figueiredo, B., Bifulco, A., Pacheco, A., Costa, R., \& Magarinho, R. (submetido) Teenage pregnancy, attachment style and depression: A comparison of teenage and adult pregnant women in a Portuguese series. Attachment \& Human Development.

Figueiredo, B., Pacheco, A., \& Magarinho, R. (2005). Grávidas adolescentes e grávidas adultas: Diferentes circunstâncias de risco? Acta Médica Portuguesa, 18, 98-105.

Fleming, A. S., Rubble, D. N., Flett, G. L., \& van Wagner, V. (1990). Postpartum adjustment in first-time mothers: changes in mood and mood content during the early postpartum months. Developmental Psychology, 26 (1), 137-143.

Geller, P. (2004). Pregnancy as a stressful life event. CNS Spectrum, 9 (3), 188-97.

Hazan, C., \& Shaver, P. (1987). Romantic love conceptualized as an attachment process. Journal of Personality and Social Psychology, 52, 511-524.

Kirkpatrick, L. A., \& Hazan, C. (1994). Attachment styles and close relationships: A four-year prospective study. Personal Relationships, 1 (2), 123-142.

Koback, R., \& Hazan, C. (1991). Attachment in marriage: Effects of security and accuracy of working models. Journal of Personality and Social Psychology, 60, 6, 861-869.

Levy, M. B., \& Davis, K. E. (1988). Lovestyles and attachment styles compared: Their relations to each other and to various relationship characteristics. Journal of Social and Personal Relationships, 5, 439-471. 
Matthey, S., Barnett, B., Ungerer, J., \& Waters, B. (2000). Paternal and maternal depressed mood during the transition to parenthood. Journal of Affective Disorders, 60, 75-85.

McCarthy, G., \& Taylor, A. (1999). Avoidant/ambivalent attachment style as a mediator between abusive childhood experiences and adult relationship difficulties. Journal of Child Psychology and Psychiatry, 40 (3), 465-477.

Michelson, K. D., Kessler, R. C., \& Shaver, P. R. (1997). Adult attachment in a nationally representative sample. Journal of Personality and Social Psychology, 73 (5), 1092-1106.

Pacheco, A., Costa, R., \& Figueiredo, B. (2003). Estilo de vinculação, sintomatologia psicopatológica e qualidade da relação com as figuras de suporte, com o terapeuta, e com o bebé (estudo exploratório). International Journal of Clinical and Health Psychology, 3 (1), 35-59.

Pajulo, M., Savonlahti, E., Sourander, A., Helenius, H., \& Piha, J. (2001). Antenatal depression, substance dependency and social support. Journal of Affective Disorder, 65 (1), 9-17.

Pajulo, M., Savonlahti, E., Sourander, A., Piha, J., Helenius, H. (2001). Prenatal maternal representations: Mothers at psychosocial risk. Infant Mental Health Journal, 22 (5), 529-544.

Rholes, W. S., Simpson, J. A., Campbell, L., \& Grich, J. (2001). Adult attachment and the transition to parenthood. Journal of Personality and Social Psychology, 81 (3), 421-435.

Ritter, C., Hobfoll, S., Lavin, J., Cameron, R., \& Hulsizer, M. (2000). Stress, psychosocial resources, and depressive symptomatology during pregnancy in low-income, inner-city women. Health Psychology, 19 (6), 576-585.

Rubertsson, C., Waldenstroem, U., \& Wickberg, B. (2003). Depressive mood in early pregnancy: Prevalence and women at risk in a national Swedish sample. Journal of Reproductive and Infant Psychology, 21 (2), 113-123.

Shaver, P. R., \& Hazan, C. (1993). Adult romantic attachment: Theory and evidence. In D. Perlman \& W. Jones (Eds.), Advances in personal relationships (vol. 4, pp. 29-70). London: Kingsley.

Simpson, J. A. (1990). Influence of attachment styles on romantic relationships. Journal of Personality and Social Psychology, 59, 971-980.

Sroufe, L., \& Waters, E. (1977). Attachment as an organizational construct. Child Development, 48, 1184-1189.

Van Ijzendoorn, M. H., \& Bakermans-Kranenburg, M. J. (1996). Attachment Representations in Mothers, Fathers, Adolescents, and Clinical Groups. A Meta-Analytic Search for Normative Data. Journal of Consulting and Clinical Psychology, 64, 8-21.

Vizziello, G. F., Antonioli, M. E., Cocci, V., \& Invernizzi, R. (1993). From pregnancy to motherhood: the structure of representative and narrative change. Infant Mental Health Journal, 14 (1), 4-15.

Ward, M. J., \& Carlson, E. A. (1995). Associations among adult attachment, representations, maternal sensitivity, and infant-mother attachment in a sample of adolescent mothers. Child Development, 66, 69-79. 